\title{
Stainless steel double loop appliance to correct ectopically positioned maxillary permanent first molar
}

\author{
Maen Mahfouz \\ Department of Orthodontics and Pediatric Dentistry, Arab American University, Jenin, Palestine \\ Email: mnmahfouz2005@yahoo.com
}

Received 23 December 2013; revised 29 January 2014; accepted 6 February 2014

Copyright (C) 2014 Maen Mahfouz. This is an open access article distributed under the Creative Commons Attribution License, which permits unrestricted use, distribution, and reproduction in any medium, provided the original work is properly cited. In accordance of the Creative Commons Attribution License all Copyrights (C) 2014 are reserved for SCIRP and the owner of the intellectual property Maen Mahfouz. All Copyright (C) 2014 are guarded by law and by SCIRP as a guardian.

\section{ABSTRACT}

Ectopic eruption is the abnormal eruption of a permanent tooth that often causes root resorption of an adjacent primary tooth which can be noted during routine dental radiographic evaluation. The mesial eruption of the permanent first molar may be a local eruption problem or may indicate developmental arch circumference deficiency requiring further consideration. Early treatment is mandatory to move the ectopically erupting tooth away from the tooth it is resorbing to allow the tooth to erupt into its normal position, maintaining a normal arch circumference. Although much has been written about ectopic eruption of the maxillary first permanent molar, no case report mentions correction of ectopically erupted maxillary permanent first molar by using double loop stainless steel.

\section{KEYWORDS}

\section{Ectopic Eruption; Maxillary Permanent First Molar; Stainless Steel}

\section{INTRODUCTION}

Ectopic eruption is one of eruption disorders seen during the transitional dentition period in children. Ectopic eruption reflects the eruption of a tooth in an abnormal position [1]. The most frequently found ectopic teeth are the maxillary first permanent molars and canines, followed by the mandibular canine, mandibular second premolar, and the maxillary lateral incisors [2,3].

Its prevalence varies from $2 \%$ to $6 \%$ depending on the population studied [4,5]. According to Moyers [6], 3\% of American children present this anomaly. In cleft palate patients, a higher prevalence of $25 \%$ has been reported [7]. Siblings of affected children experience this inci- dence five times greater than the general population [8]. This anomaly was observed more frequently in boys than in girls $[4,5]$.

The cause of ectopic eruption of the maxillary first permanent molar is not well known and is considered to have a multifactorial etiology $[9,10]$. Before emerging, the tooth germ of the maxillary first molar is oriented downward, backward, and outward. As eruption continues, the tooth adopts a more vertical position [11].

Several etiologic factors have been suggested for ectopic eruption of first permanent molars, including inadequate arch length, lack of growth in the posterior region of the jaw, mesially inclined eruption path of first permanent molars, and abnormally large first permanent molars [12-14]. The literature also suggests that ectopic eruption is an indicator of developing inadequate arch circumference and, therefore, is likely to result in a crowded permanent dentition. Kennedy and Turley [15] suggested that patients presenting with ectopic eruption of molars require careful management.

Two types of permanent first molar ectopic eruption can be distinguished $[4,16,17]$. In the reversible type, the molar, after resorbing the distal root surface of the second primary molar, becomes free and erupts into its normal position in the dental arch. In the irreversible type, the erupting first permanent molar becomes blocked by the second primary molar, and the permanent molar remains in this locked position until treatment is provided or premature exfoliation of the primary molar occurs.

Ectopic eruption can be diagnosed clinically on the basis of partial or total failure to emerge [18]. The diagnosis is usually done at a routine radiographic examination before the eruption of these teeth, usually between five and seven years of age. The maxillary first permanent molar is regarded as ectopically erupted if on the radiograph it appears in a superposed image and im- 
pacted in the distobuccal root of the deciduous tooth $[19,20]$.

Several techniques for the correction of the ectopically positioned PMFM have been reported and they range from orthodontic band and springs [21,22], deimpactors [23], elastomeric separator [24], cervical traction [25] and helical springs to Croll's bilateral band and wire appliance [26] and Grim's removable Hawley’s appliance with spring [27]. However, each technique has various disadvantages.

The aim of this article is to present a case of ectopically positioned permanent maxillary first molar which was successfully corrected using chairside double loop SS.

\section{CASE REPORT}

A 7 years old girl with her mother attended to my orthodontic clinic with chief compliant of pain on biting related to the upper right E. She was in early mixed dentition. The general health of patient was good with no significant medical history.

Records: OPG was taken for diagnosis.

Extraoral examination: mesomorphic built, normal gait and posture. Face was mesocephalic with competent lips. Profile was straight (Figures 1, 2 and 3).

Intraoral examination: Soft tissues normal.

Erupted teeth:
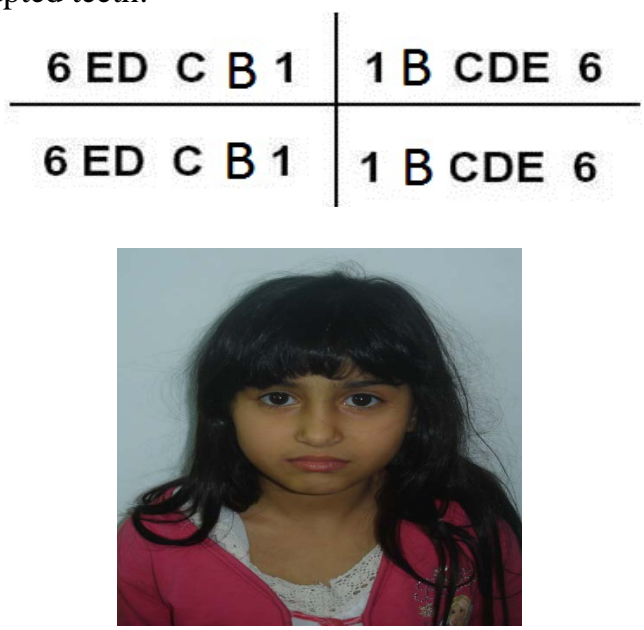

Figure 1. Frontal-extraoral view.

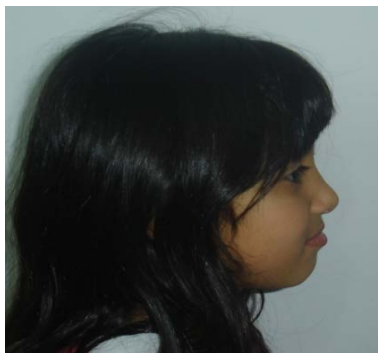

Figure 2. Profile view.
Maxillary arch: symmetrical with upper permanent central incisors spaced.

Mandibular arch: symmetrical.

Intra occlusal examination (Figures 4, 5, 6, 7, 8, 9 and 10).

1) Primary canine relationship is neutro cuspid.

2) Primary molar relationship is straight step.

3) Overjet and overbite is normal.

Radiographic examination by panoramic view has re-

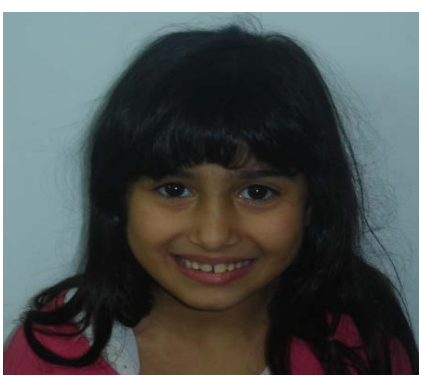

Figure 3. Smile view.

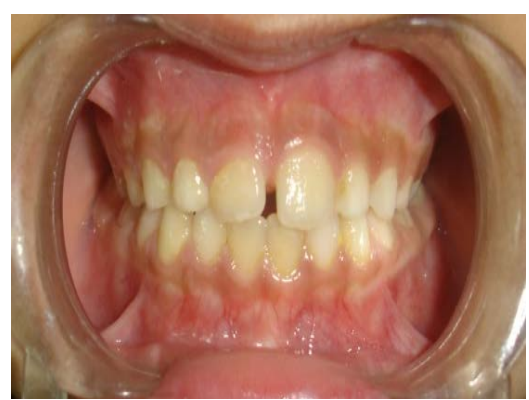

Figure 4. Frontal-intraoral view.

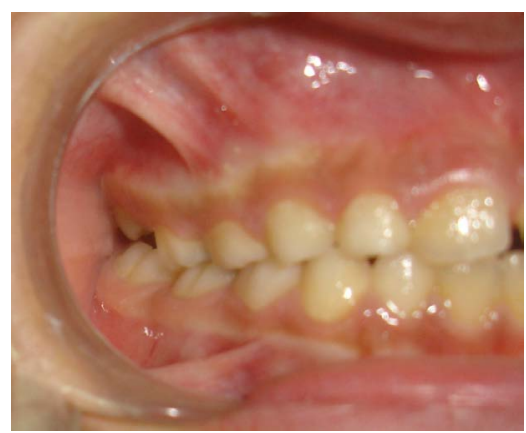

Figure 5. Right side-intraoral view.

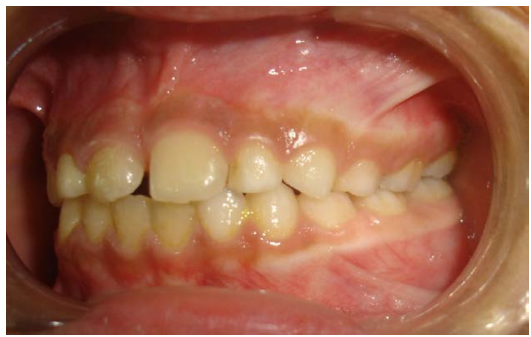

Figure 6. Left side-intraoral view. 


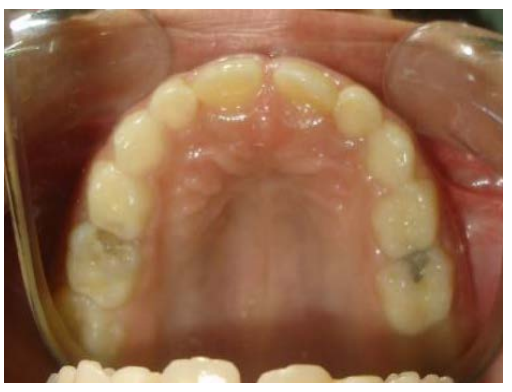

Figure 7. Upper occlusal view.

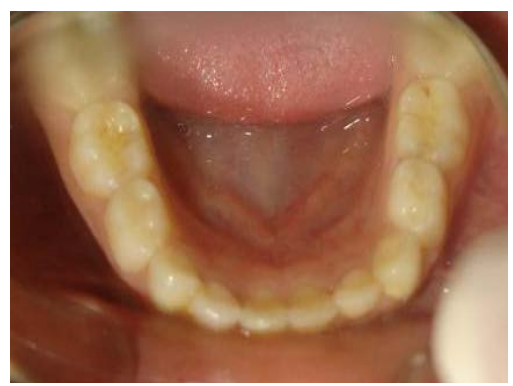

Figure 8. Lower occlusal view.

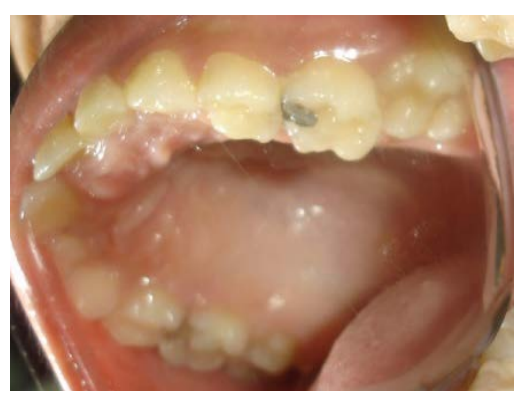

Figure 9. Intraoral view of ectopically erupted PMFM.

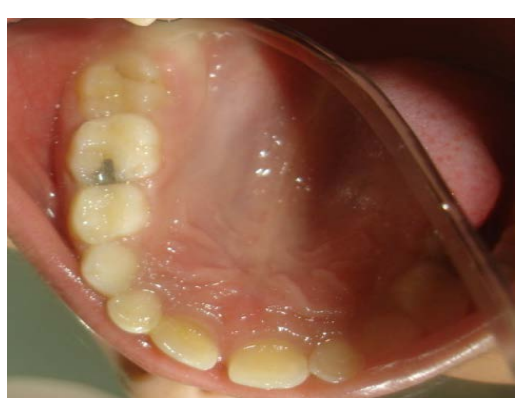

Figure 10. Occlusal View of ectopically erupted PMFM.

vealed that all permanent unerupted teeth present except third molars, she has an amalgam filling on the upper right $\mathrm{E}$ with distobuccal root resorption, the upper permanent 6 is partially erupted and rotated mesiopalatally, while mesial portion of the occlusal surface of the upper right 6 is locked beneath the distal portion of the upper right $\mathrm{E}$ and deep carious lesion involving upper left $\mathrm{D}$ and E (Figure 11).

Diagnosis:

The clinical examination revealed that the upper right E has amalgam filling on the occlusal surface with no preiapical pathology and on percussion there is Pain, the upper permanent 6 is partially erupted and rotated mesiopalatally, the mesial part of the occlusal surface of the upper right 6 is blocked at the level of the gingiva against the distal surface of the upper right $\mathrm{E}$ while in the contralateral side it is normal. Carious lesions were found on the upper left $\mathrm{D}$ and $\mathrm{E}$.

Treatment Objectives:

Relief pain related to the upper right $\mathrm{E}$ due to severe resorption with pulp exposure caused by ectopic eruption of the upper right first permanent molar, Correction the pathway of first permanent molar eruption and maintenance the integrity of arch circumference.

Treatment plan: fixed orthodontic treatment by using double loop SS for the correction of ectopically erupted upper right permanent 6 .

Treatment procedure:

Behavior management for this child has been carried out through TSD and indirect modeling through showing her photographs of different cases in her age which have been treated in my orthodontic clinic, after she became familiar with dental office, treatment started so bondable buccal tubes placed on the buccal surfaces of upper first permanent molar and upper first primary molar (Figure 12). After that the second primary molar is anesthetized by infiltration technique buccally and palataly to do extraction of this tooth as it has severe resorption with pulp exposure due to ectopic eruption of 6 . Finally a double

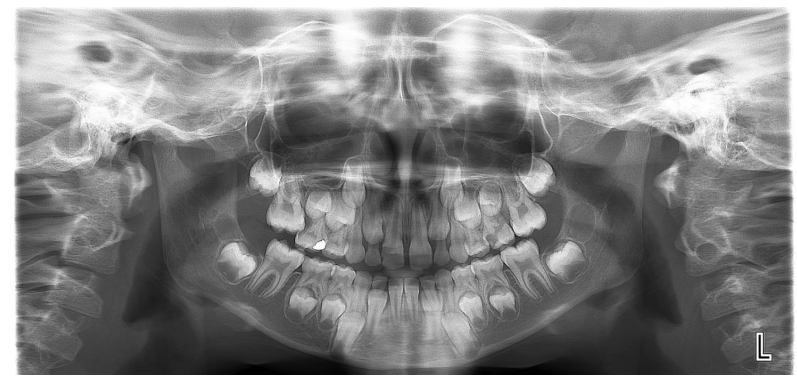

Figure 11. OPG.

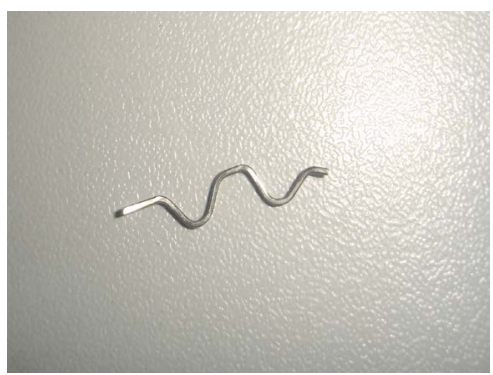

Figure 12. Double loop SS. 
loop round stainless steel arch wire is placed in the bondable buccal tubes (Figures 13, 14, 15, 16 and 17).

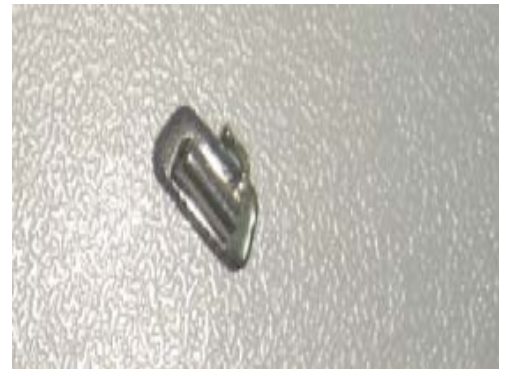

Figure 13. Bondable buccal tube.

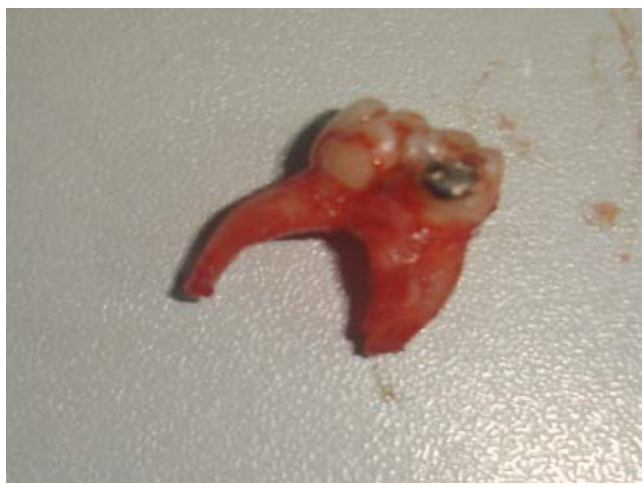

Figure 14. Extracted E.

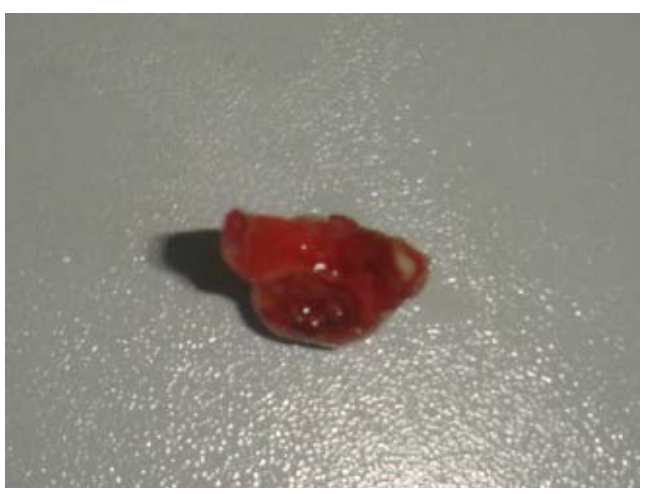

Figure 15. Extracted E.

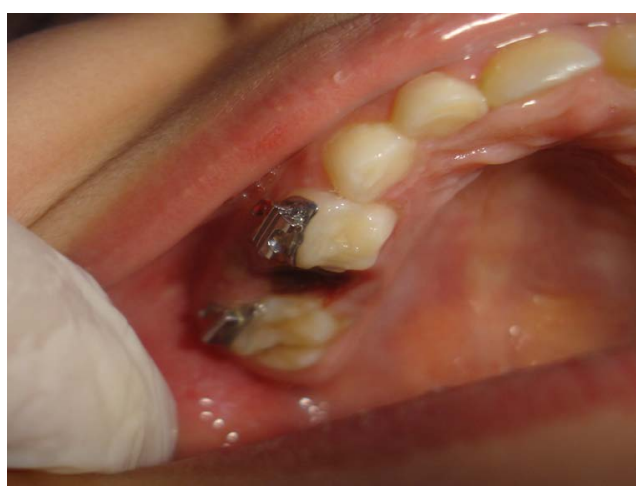

Figure 16. Initial-treatment.
After 3 weeks an assessment of the clinical situation has been done so the upper permanent 6 is fully erupted, the mesiopalatally rotation is corrected, the mesial part of the occlusal surface of the upper right 6 is above the level of the gingival which indicates the correction as in the contralateral side (Figures 18 and 19).

The child and her mother were asked to apply oral hygiene measures like tooth cleaning, avoiding any habit or eating can damage the appliance and how to care with orthodontic appliance. The total treatment time was 4 weeks and appliance was not removed to work as space maintainer for the coming successor 2nd permanent premolar (Figure 20).

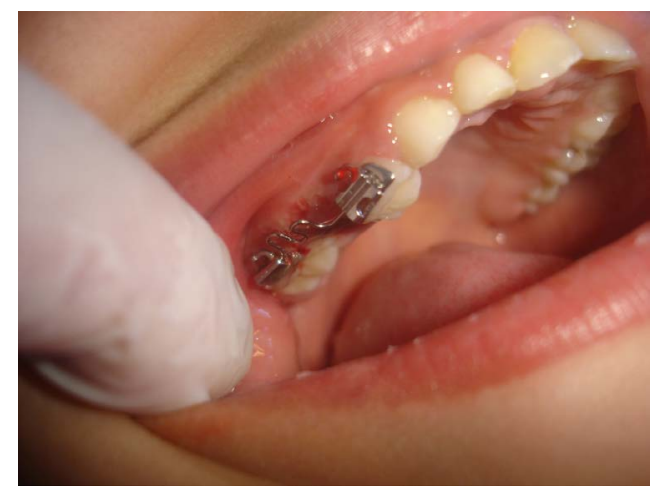

Figure 17. Initial-treatment.

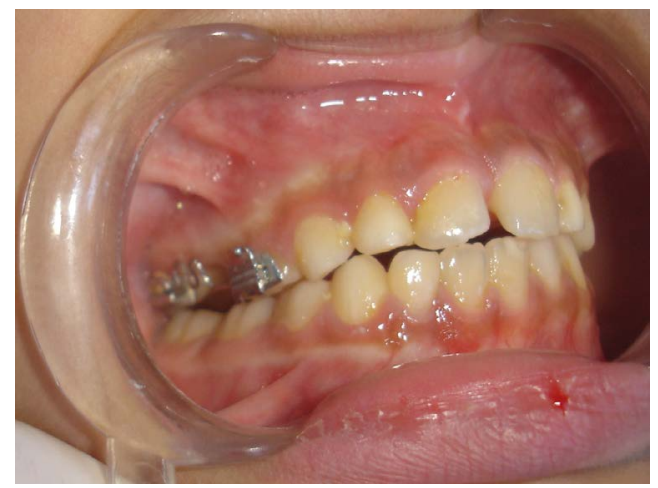

Figure 18. Mid-treatment (3 weeks).

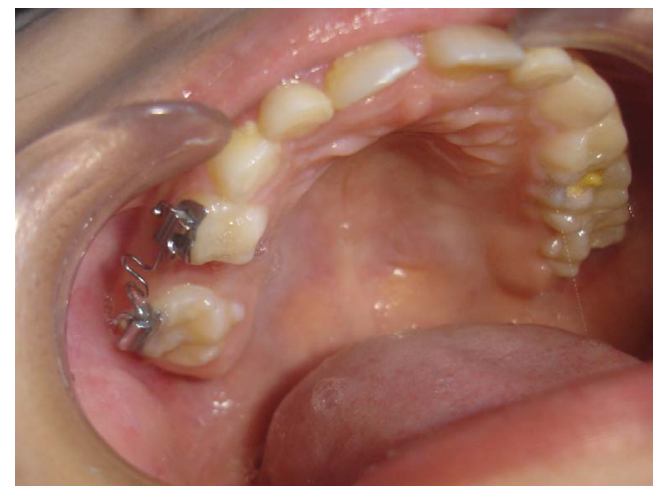

Figure 19. Mid-treatment (3 weeks). 


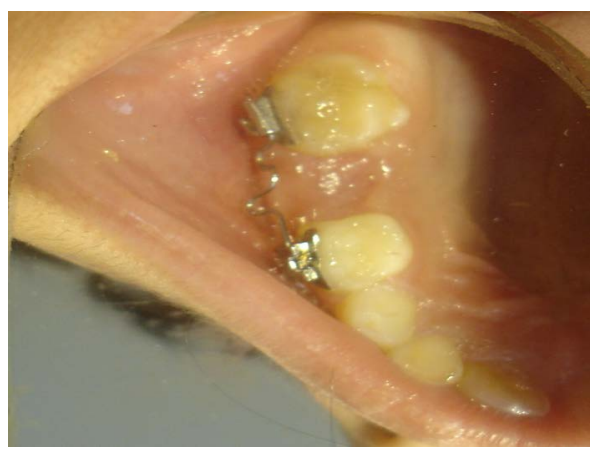

Figure 20. Post-treatment (4 weeks finished).

\section{DISCUSSION}

Ectopic eruption of permanent maxillary first molar, a developmental disorder in path of eruption was first described by Chapman in 1923 [28].

Methods of grading the severity of ectopic eruption of PMFM have been reported in the literature $[19,20]$. Barberia-Leache et al. [17] classified this problem into 4 grades according to the magnitude of the primary second molar distal root resorption.

Grade I: Mild-limited resorption to cementum or with minimum dentin penetration

Grade II: Moderate-resorption of the dentin without pulp exposition

Grade III: Severe-resorption of the distal root leading to pulp exposure

Grade IV: Very severe-resorption that affects the mesial root of the primary second molar

Regarding correction, grades I and II normally self corrected spontaneously and grades III and IV remain impacted. However, there was some self-corrected grade III cases and some grade I cases that stayed impacted [17].

This pathology should be taken into consideration during a clinical examination. The unilateral or bilateral delay in the emergence of the maxillary first permanent molar [29] or an eruption path in which the distal cusps are emerging before the mesial cusps should make us think of this process [30]. A follow-up radiograph through time will allow differential diagnosis between reversible and irreversible ectopic eruption. In both cases, a pathological resorption of the distal root of the deciduous second molars is produced. The irreversible form could cause exfoliation of the deciduous second molars with the resulting mesial migration of the first molar occupying the space of the second premolar. This will provoke a decrease in arch length and delay the eruption of the maxillary second premolars [31,32].

A permanent molar with a minor degree of impaction, limited to the middle or less of its marginal border, usually will spontaneously correct. However, if there is a greater degree of impaction including the complete mar- ginal border, it usually does not self-correct. In general, resorption is stopped once the first permanent molar corrects its eruption path and secondary dentin is usually deposited in the area of resorption, obliterating the exposed dentin [33,34]. When ectopic eruption is reversible, the eruptive path is self-corrected by seven years of age in the majority of cases [35].

In this case report, irreversible ectopic eruption of maxillary first permanent molars is presented. Ectopic eruption of molars usually is associated with resorption of an adjacent primary tooth, frequently leads to molar impaction. The patient described in this case report had all these associated clinical findings in addition to pain which is the motivating factor to seek treatment.

In this case extraction of the second primary molar is decided to be done for three factors, first: the pain associated with this pathology, second: severe resorption and third: complete mesial marginal border impaction. The double loop SS that is used to correct ectopically positioned permanent molar also it functions as a space maintainer after correction.

Although different methods have been suggested for distalizing the ectopic molar, each technique has various disadvantages [15,27].

Elastomeric separators [24], brass separating wire [36], helical springs [22] and Humphrey's appliance [37,38] all these methods used without extraction of the second primary molar so they are not applicable in cases associated with extraction of the second primary molars.

Auychai et al. [39] by sectioning the distal part of the adjacent second primary molars which is similar to that described by Sanders [40] since this treatment results in arch length loss equal to about half the width of the primary second molar.

When the relative simplicity of such treatment is weighed against the severity of the consequences of untreated cases of ectopic eruption, it can be argued that early intervention is important to assure a normal eruption pathway while minimizing detrimental effects on the developing occlusion.

\section{CONCLUSIONS}

1) Double loop SS appliance is an effective interceptive treatment modality for the correction of ectopically erupting PMFM in children, during mixed dentition period with limited disadvantages. Although ectopic eruption sometimes is self correcting and some authors suggest an observation before the therapy but we suggest an early treatment with double loop appliance in case of pain associated with root resorption of the second primary molar and in turn its early loss in the oral cavity.

2) More research including large sample size is required to evaluate the effectiveness of double loop SS appliance comparing with other techniques. 
3) Pediatric dentist is the pioneer in diagnosis and treatment of these cases as he/she is the primary care provider.

4) Continuous checking of primary occlusal relationship allows early correction of ectopic eruption.

\section{ACKNOWLEDGEMENTS}

First and foremost I would like to thank my Mom "Wedad Jarrad" for her valuable great support, guidance and advice.

\section{REFERENCES}

[1] Toutountzakis, N. and Kastaris, N. (1990) Ectopic Eruption of the Maxillary First Permanent Molar. Orthodontike Epitheorese, 2, 117-128.

[2] Wei, S.H. (1988) Pediatric Dentistry: Total Patient Care. Lea and Febiger, Philadelphia, 462-463.

[3] Sim, J.M. (1973) Movimientos Dentarios Menores en Niños. Editorial Mundi, Buenos Aires, 22-24.

[4] Bjerklin, K. and Kurol, J. (1981) Prevalence of Ectopic Eruption of the Maxillary First Permanent Molar. Swedish Dental Journal, 5, 29-34.

[5] Kimmel, N.A., Gellin, M.E., Bohannan, H.M. and Kaplan, A.L. (1982) Ectopic Eruption of Maxillary First Permanent Molars in Different Areas of the United States. ASDC Journal of Dentistry for Children, 49, 294-299.

[6] Moyers, R.E. (1992) Manual de Ortodoncia. 4th Edition, Editorial Medica Panamericana, Buenos Aires, 129.

[7] Carr, G.E. and Mink, J.R. (1965) Ectopic Eruption of the First Permanent Maxillary Molar in Cleft Lip and Cleft Palate Children. ASDC Journal of Dentistry for Children, 32, 179-188.

[8] Bjerklin, K. (1994) Ectopic Eruption of the Maxillary First Permanent Molar. An Epidemiological, Familial, Etiological and Longitudinal Clinical Study. Swedish Dental Journal, 100, 1-16.

[9] Barbería, E. and De Grado, M. (1994) Erupción Ectópica del Primer Molar Permanente Superior. Revisión Bibliogáfica. Parte I. Odontología Pediátrica, 3, 71-76.

[10] Yuen, S., Chan, J. and Tay, F. (1985) Ectopic Eruption of the Maxillary Permanent First Molar: The Effect of Increased Mesial Angulation on Arch Length. Journal of the American Dental Association, 11, 447-451.

[11] Nakata, M. and Wei, S. (1989) Guía Oclusal en Odontopediatria: Atlas a Color. Caracas, Venezuela, Editorial Actualidades Médico, Odontológicas de Latinoamé Rica, 14-16.

[12] Pulver, F. (1968) The Etiology and Prevalence of Ectopic Eruption of the Maxillary First Permanenmt Olar. Journal of Dentistry for Children, 35, 138-146.

[13] Bjerklin, K. and Kurol, J. (1983) Ectopic Eruption of the Maxillary First Permanent Molar: Etiologic Factors. American Journal of Orthodontics and Dentofacial Orthopedics, 84, 147-155.

http://dx.doi.org/10.1016/0002-9416(83)90179-3
[14] Raghoebar, G.M., Boering, G., Vissink, A. and Stegenga, B. (1991) Eruption Disturbances of Permanent Molars: A Review. Journal of Oral Pathology \& Medicine, 20, 159166.

http://dx.doi.org/10.1111/j.1600-0714.1991.tb00913.x

[15] Kennedy, D.B. and Turley, P.K. (1987) The Clinical Management of Ectopically Erupting First Permanent Molars. American Journal of Orthodontics and Dentofacial Orthopedics, 92, 336-345. http://dx.doi.org/10.1016/0889-5406(87)90335-0

[16] Young, D.H. (1957) Ectopic Eruption of the First Permanent Molar. Journal of Dentistry for Children, 24, 153-162.

[17] Barberia-Leache, E., Suarez-Clua, M.C. and SaavedraOntiveros, D. (2005) Ectopic Eruption of the Maxillary First Permanent Molar: Characteristics and Occurrence in Growing Children. Angle Orthodontist, 75, 610-615.

[18] van der Linden, F.P.G.M. (1990) Problems and Procedures in Dentofacial Orthopedics. Quintessence, London, 297-300.

[19] O’Meara, W.F. (1962) Ectopic Eruption Pattern in Selected Permanent Teeth. Journal of Dental Research, 41, 607-616. http://dx.doi.org/10.1177/00220345620410031301

[20] Andlaw, R.J. and Rock, W.P. (1978) A Manual of Pedodontics. 2nd Edition, Churchill Livingstone, Edinburgh, 138-140.

[21] Kennedy, D.B. (1985) A Bonded Appliance to Correct Ectopically Erupting Permanent Molars. Pediatric Dentistry, 7, 224-226.

[22] Garcia-Godoy, F. (1982) Correction of Ectopically Erupting Maxillary Permanent First Molars. Journal of the American Dental Association, 105, 244-246.

[23] Venn, R.J. (1985) Ectopic Eruption of Permanent First Molars: A Clinical Technique. Journal of Pedodontics, 10, 81-88.

[24] Hirayama, K. and Chow, M.H. (1992) Correcting Ectopic First Permanent Molars with Metal or Elastic Separators. Pediatric Dentistry, 14, 342-344.

[25] Kurol, J. and Bjerklin, K. (1984) Treatment of Children with Ectopic Eruption of the Maxillary First Permanent Molar by Cervical Traction. American Journal of Orthodontics, 86, 483-492. http://dx.doi.org/10.1016/S0002-9416(84)90354-3

[26] Croll, T.P. (1984) Correction of First Permanent Molar Ectopic Eruption. Quintessence International, 15, 12391246.

[27] Grimm, S.E. (1988) Treatment of Ectopically Erupting Molars. Journal of Clinical Orthodontics, 22, 512-513.

[28] Chapman, M.H. (1923) First Upper Permanent Molars Partially Impacted against Second Deciduous Molars. International Journal of Oral Surgery, 9, 339-345.

[29] Heikkinen, T., Alvesalo, L., Osborne, R.H. and Tienari, J. (2001) Tooth Eruption Symmetry in Functional Literalities. Archives of Oral Biology, 46, 609-617. http://dx.doi.org/10.1016/S0003-9969(01)00019-X

[30] Campbell, O.A. (1991) Ectopic Eruption of the First Per- 
manent Molar. Journal of the American Dental Association, 62, 62-65.

[31] Barbería, E. and De Grado, V.M. (1994) Erupción Ectópica del Primer Molar Permanente Superior. Revisión Bibliogáfica. Parte II. Odontología Pediátrica, 3, 113118.

[32] Stewart, R.E., Barber, T.K., Troutman, K.C. and Wei, S.H. (1982) Pediatric Dentistry. Mosby Co, St Louis, 869-870.

[33] Starkey, P. (1961) Infection Following Ectopic Eruption of Permanent Molars: Case Report. Journal of Dentistry for Children, 28, 327-330.

[34] Gleerup, A., Bjerklin, K. and Kuroll, J. (1995) Discriminant Analysis in Treatment Evaluation of Ectopic Eruption of the Maxillary First Permanent Molars. European Journal of Orthodontics, 17, 181-191. http://dx.doi.org/10.1093/ejo/17.4.281

[35] Kurol, J. and Berjklin, K. (1982) Resorption of Maxillary Second Primary Molars Caused by Ectopic Eruption of the Maxillary First Permanent Molar: A Longitudinal and
Histological Study. ASDC Journal of Dentistry for Children, 49, 273-279.

[36] Seow, W.K. (1984) The Application of Tooth Separation in Clinical Pedodontics. ASDC Journal of Dentistry for Children, 51, 428-430.

[37] Humphrey, W.P. (1962) A Simple Technique for Correcting an Ectopically Erupting First Permanent Molar. ASDC Journal of Dentistry for Children, 29, 176-178.

[38] Nagaveni, N.B. and Radhika, N.B. (2010) Interceptive Orthodontic Correction of Ectopically Erupting Permanent Maxillary First Molar. A Case Report. Virtual Journal of Orthodontics.

[39] Auychai, S., Feigal, R. and Walker, P. (1996) Management of Mandibular Molar Ectopic Eruption Using Primary Molar Hemisection: Case Report. American Academy of Pediatric Dentistry Journal, 18, 5.

[40] Sanders, B. (1981) Oral and Maxillofacial Surgery. In: Stuart, R.E., Barber, T.K., Troutman, K.C. and Wei, S.H.Y., Eds., Pediatric Dentistry, CV Mosby Co, St Louis, 973990.

D: First Primary Molar

E: Second Primary Molar

PMFM: Permanent Maxillary First Molar

6: Permanent Maxillary First Molar

OPG: Orthopantogram 